2006-2549: DOCTORAL DEGREES IN ENGINEERING TECHNOLOGY: WHAT ARE THE REAL ISSUES?

Lawrence Wolf, Oregon Institute of Technology 


\section{Doctoral Degrees in EngINEERING TeCHNOLOGY: WHAT ARE THE REAL ISSUES?}

\section{Abstract}

In 1982 I published a paper in the ASEE, Journal of Engineering Education, which attempted to bring the issues concerning graduate education in engineering technology into focus. ${ }^{i}$ At that time it was the masters degree that was the point of contention. Engineering technology educators wanted masters degrees ${ }^{\mathrm{ii}}$, but the broader engineering education community was still ambivalent about even the bachelor degree in engineering technology. Yet that paper made it through the editorial committee of Engineering Education. Master's degrees in engineering technology are now established even though there is still some reticence. But, perhaps the time has now arrived for a broader dialog about engineering technology at the doctoral level.

My paper first identified five "non-issues" that I thought should be cleared from the table so that the "real" issues could begin to see the light of day. The nonissues were that masters degrees would provide more status for engineering technology, that they would result in better funding for engineering technology education, that they would provide a supply of teachers, that ET should not be dead-ended, and that the master's was the natural progression for ET education. While all these were interesting and worthwhile discussions within the ET community, they would not be the ones that would decide the question beyond that community.

The paper went on to suggest instead four "real issues." Those were the intellectual issues that would finally prevail in the intensely academic enterprise that was and is the American university. Those issues were the body of knowledge, the components of research and scholarship at the master's level, the faculty criteria, and the admissions criteria. This paper revisits the format of the 1982 paper on the master's and suggests some appropriate issues for doctoral degrees in engineering technology.

If master's degree programs in engineering technology were a source of contention two decades ago, the establishment of doctoral program can be expected to be the subject of considerable deliberation within institutions of higher education. This will involve a cascade of university governance committees that may yet be fraught with the biases that have accompanied technology programs in the past. There will be further issues of institutional mission constraint and exclusivity since the authorization for doctoral programs is less widely distributed than are those for master's degrees. Engineering technology has managed to cope well with the biases and political challenges but its experience at the graduate level is still limited. So the philosophical questions will still be the tough ones. 


\section{The Non-Issues}

In the format of that earlier paper, let me again try so move to the side some frequently raised arguments that may tend to cloud the central question.

\section{1) "Engineering technology will have more status if it has doctoral programs."}

If status seeking is a fault, it is a fault shared not only by the institutions themselves but also by those who seeking a university education at any level. Graduate study and even the very choice of a school are steeped in considerations of status. While technologists may feel disadvantaged on this score, we must not take the desire for stature to be a sound intellectual reason for having doctoral study or not. Doctoral programs do not exist merely to make people feel good.

2) 'Is engineering technology 'sophisticated' enough to be taught on the doctoral level at a university?"

Remnants of that elitist argument against technology might yet persist even though technology is today much more respectable. Now economists classify the "technology industry" as a major sector of the world economy. On any day one can do a Google search on "technology" and get a couple of billion hits. Terms such as technologist and technical fellow are used to recognize the highest achievers at places like Boeing, Intel, and Monsanto. ${ }^{\text {iii }}$ We even run across indicators that technology has actually become a respected and necessary intellectual endeavor, such as a quote by Thomas Grose, set forth in bold type in the September issue of the ASEE's, Prism, in his article Narrowing the Gap. It reads, "The core value of engineering is using technology in the service of humanity." "iv In my forty years of working primarily under the flag of technology I have now seen it go from, what can best be described as the "engineer's little helper" to being right up, there, with math and science as being what engineering brings to the service of humanity. It may be accurate and sufficient to simply define engineering technology as the technology in support of engineering.

3) "More advanced-degree programs will enable engineering technology education to gain more formula money (at tax-supported institutions) or tuition money (at private institutions)."

This is an education financing argument, not a valid philosophical reason for providing graduate programs. Furthermore, it may even be false. Although more funds may be on the table, doctoral programs are still very much more costly.

4) "Engineering technology graduates should not be dead-ended."

This statement has a noble ring but it is no more a reason to establish the doctorate in engineering technology than it was for the masters. Engineering technology graduates 
are just as mobile as graduates in most other fields. Many go on to degrees in business administration, engineering, and education.

5) "Many said bachelor degrees wouldn't last. But they did. Then we had master's degrees and they said they wouldn't last. But they did. Isn't it now natural to have doctor's degree in technology?"

Academic governance committees and state coordinating boards have been down that road before. Lots of things last, but that doesn't mean that they should be a part of any particular university. It takes other reasons.

\section{The Real Issues}

After the biases, politics, and the emotional arguments have been put aside, there remain at least six basic philosophical issues (rather than only four for the master's), which need to be resolved before any institution should embark on a journey into the $\mathrm{PhD}$ in engineering technology. These true issues are: 1. the body of knowledge; 2 . what constitutes research; 3 . faculty criteria; 4 . student criteria; 5 ; the preparation of teachers for the discipline; and 6 . the value of such study to the larger world beyond the university.

1) "What is the body of knowledge to be addressed by the ET doctor's degree program? And is that body of knowledge of appropriate sophistication for graduate study?"

It continues to be difficult to define engineering technology in terms of the traditional "big four" fields of mechanical, electrical, civil and chemical engineering; because it is a challenge to define engineering technology independently of engineering. Technology is sometimes criticized as being a distinction without a difference. Contrasting it against engineering invites a comparison that is usually unfavorable in terms of the second part of this question having to do with level and sophistication. The engineering disciplines have had more than a century and a half to mature. The evolution of engineering technology may actually be one of the signs of the maturation of engineering, although many will be loath to see it as such.

There are no natural boundaries, like rivers and mountains, between the terrains of engineering technology and engineering. One must not to look for demarcations or boarders as setting one off the one from the other, but rather to discover the differences of positions of the centers. Finding the center of engineering technology will not be easy. I have no answers except that engineering has since the Grinter Report evolved to be much more than quantitative, its has become analytical at its heart. Technology, on the other hand, has become highly anecdotal at its core. While anecdotal information may not be favored in a data driven culture, much of what it takes to make technology work cannot be derived from an equation or an algorithm. You just have to know the story or more precisely, the history. 
For example, in my forty-year career in education I have fortunately been able to take three sabbaticals in my struggle to keep up to date. In the first case, I was productive within the second week of my arrival. All I needed was a place to work, and a charge number for the mainframe computer. In those days one wrote one's own programs and was able to use virtually all the instrumentation in the lab.

The second sabbatical required about a month for me to get settled. That time, my host organization needed get a computer for my personal use, passwords, and software packages.

In the third case it took several months because I needed not only my own computer, passwords, and programs; but also accesses through firewalls to shared networks, files, and concurrent-engineering software licenses. You couldn't just get all these authorizations simultaneously. They had to come sequentially. The massive data moving potential and storage capacity may have greatly reduced the complexity of the analytical work; but the anecdotal knowledge about compatibility and connectivity, security considerations, software and system usage, and the characteristics and capability and of the equipment had become much more detailed and involved. You just had to know or discover the details before you could position yourself within the system so that you could operate. I suspect that the center of the body of knowledge for engineering technology may lie somewhere within in those kinds of anecdotal details.

2) "What constitutes research and scholarship in engineering technology education?"

Research is needed in graduate education in order to maintain, expand, and define the body of knowledge. At the PhD level, not only the faculty, but also the students, must be doing research. That is the value system of doctoral education.

While graduate instruction at the master's level is, in fact, research-centered, it is not intended to produce finished researchers. At the PhD level on the other hand it is expected to actually finish the job and produce graduates who are in fact researchers.

We technologists find ourselves hampered by a legacy of a somewhat negative attitude towards research. At the time of my earlier paper, technologists often pointed to a conflict between research and excellent teaching. Tales abounded of individual professors that may have ignored teaching for the sake of their research. But, we technologists now are much more accepting of the symbiosis between research in technology. After all, much of the wonderful technology that we enjoy today came directly from that partnership.

The word "technology" comes from the Greek words for the study of an art or skill - the study of techniques. The technologist can be defined as one who studies techniques. Because engineering has focused more and more on the applications of mathematics and science, much room is left for technologists to concentrate on the business and industrial techniques that may have come from non-scientific sources and that may be qualitative rather than quantitative. These techniques are far beyond the rules of thumb developed by trial and error. They may even be artistic. Nevertheless, they are just as important to an 
enterprise as the techniques that have been generated by science and mathematics. Modern technology owes as much to the crafts and the market place as it does to science and the academy.

In the earlier days of the computer, engineers made great strides in applying this new tool to analyze things that previously were thought too complex to be analyzed, driving the predisposition to analysis. But even further development of computers, making them essentially cheap and far more powerful than most of us could have dreamed, has opened even more opportunities for research in technology. Concurrent engineering has eliminated the gap between manufacturing and product design. The global opportunities, and competitors, that sprung from the World Wide Web have made time-to-market considerations and product-life-management paramount to the business of producing goods and services. Team efforts, bringing together many different points of view, are the way business is done now, and technologists are key players on those teams. And, today you have to be "lean" to be competitive. These are all areas where engineering technologists are players, and where research can be done.

3) "What are the criteria for the graduate faculty?"

Because not all members of the faculty in a graduate-degree granting department are members of the doctoral faculty, technology faculty may feel threatened that their ranks will be divided. Worse yet, in the view of some technology faculty, is that the doctor's degree is required to teach in virtually every graduate school today. Because the masters degree was once explicitly written in ABET criteria as the "terminal degree" for ET faculty, many technology faculty don't have doctorates themselves. Thus they have concerns about being left behind, or of no longer being the opinion leaders in their department. But things have changed dramatically in twenty-four years. Back then few people that had a doctorate in an engineering-related field were being appointed to faculty positions in engineering technology. Now, it is not unusual to see ET faculty positions advertised as "doctorate preferred".

While the shock of the doctorate is now mostly past, attention must turn to research and publication requirements for faculty. Industrial experience, which has always been the key selection criterion for engineering technology, might need to be augmented by something like industrial networking, continuing connectivity, or having been among the recognized founders of the technology. In this environment of rapid technological change, industrial experience alone has an abbreviated half-life. We are wanting for something more sustainable.

4) "What are the criteria for student admission and graduation?"

ET faculty culture is one of adapting instruction to the needs of the students. Complaints of impersonal advisers and professionally detached faculty are very rare in engineering technology. And, I personally believe that this will be even more so in the future. Nevertheless, a good graduate program cannot admit all applicants, and it will not graduate all who are admitted. 
The discussion of admissions and graduation criteria is difficult, because so many teachers of engineering technology have been heavily influenced by the "open door" philosophy of education. While the open door in its purest form is altruistic, many institutions professing this philosophy might be suspected of being motivated primarily by entrepreneurial considerations such as the desire to generate enrollment or tuition revenue. Some in the academy are suspicious of such motives at any level and will find it intolerable at the doctoral level.

\section{5) "Engineering technology needs a supply of teachers."}

While true for the doctorate, I argued that this was not a valid reason to establish master's programs in the field of engineering technology. Technology teaching is more content oriented than methods-oriented. It is preferable that technology faculty be master technologists and journeyman teachers rather than journeyman technologists and master teachers. And, that is also of prime importance at the doctoral level.

But at the doctoral level, we are talking about "disciples." You can't have a well-defined mature discipline without disciples. The fact that engineering technology has been so slow at defining its body of knowledge, compared to say the discipline of computer science, may be due to the fact that engineering technology did not develop PhDs early on.

\section{6) The value of the program to the world beyond the university.}

Notably absent in the five points discussed so far, is the question of employer demand which has been an extremely important point to technologists. It is equally important to any lay boards that may be considering a doctoral program. Most graduate curricula do not have the well-defined employment prospects to justify an individual's investment in further study. Even in engineering, full-time graduate study is difficult to rationalize economically when one considers the income that a B.S. degree holder must forfeit for full-time study. Yet few would argue that graduate study opportunities in engineering fields should therefore not be available.

Employment surveys are required for the approval of any graduate program, even though the employment market for technical personnel is variable in place and in time. And even though individual employer responses to a needs survey tend to be highly unreliable when considering a new technical program at any level. So employers simply cannot be expected to be able to visualize with much accuracy the product of a graduate program in a new field. For doctoral programs, the expected employers will be mostly those educational institutions that will hire the graduates as faculty members.

While employer demand deserves to be a part of any good curriculum proposal in technology, I think that the debate should be taken up a notch to a higher level in the case of a doctoral program in technology. That plane should be the value of the program to the world beyond the university. Technology is now seen to be exceedingly important to 
the world's economy. It is not an exaggeration to find technology being lauded as important even to the world's survival, while at the same time the press is full of instances of misapplication of technology that are blamed for what might even become the world's demise. While this is dangerously close to hubris to say, technology is in fact a really important and its study is deserving of being the life's work of scholars from many disciplines. Surely engineering technology should be among them. That should be the level of discussion for a doctor's degree in engineering technology.

\section{Conclusion}

I believe that doctoral programs will finally become widely available in all of the technologies. Good ones will deal satisfactorily with the six issues raised: the body of knowledge, research, faculty criteria, student criteria, the supply of teachers, and the inherent value of such scholarship to the world beyond the university.

\footnotetext{
${ }^{i}$ L. J. Wolf, "Graduate Education in Engineering Technology: What are the Real Issues," Engineering Education, vol.72, nos. 1-8, May 1982 / p809, (ISSN 022-0809), ASEE, Washington, DC

ii Michael T. O'Hair, “The Masters Controversy: What Do ET Faculty Think,” Engineering Education, vol.72, nos. 1-8, May 1982 / p810, (ISSN 022-0809), ASEE, Washington, DC

iii See Boeing. COM, Intel. COM, Boeing, com and search on "Technologist" and "Technical Fellow"

iv Thomas Grose, "Narrowing the Gap," Prism, ASEE, November, 2004, p44
} 